\title{
Physical activity level in people with age related white matter changes correlates to better motor performance, lower comorbidity and higher cognitive level
}

\author{
Anna F. Pettersson ${ }^{1 *}$ (D) Lars-Olof Wahlund ${ }^{2}$, Lena Bronge ${ }^{3}$, Elisabeth Olsson', Kaarina Amberla ${ }^{4}$, \\ Hansjoerg Baezner ${ }^{5}$ and Milita Crisby ${ }^{2^{*}}$
}

\begin{abstract}
Background: Physical activity plays a pivotal role in the development of disability and may modify the negative effect of vascular risk factors on progression of both cardio and cerebrovascular disorders. The aim of this study was to evaluate the activity level in people with age-related white matter changes as identified on magnetic resonance imaging (MRI) in relation to motor performance, cognition and perceived health.

Methods: Data came from the first year follow up of one participating centers of the LADIS study. Fifty one subjects were first enrolled in the study. Complete first year follow up data was available for 41 subjects. Information on comorbidity, physical activity level, physical function, cognition, level of white matter changes and perceived health was collected. Physical activity level was classified with a yes or no question and with the Frenchay Activities Index (FAl).

Results: Only 36\% of the subjects in this study were physically active according to the yes/no question. $27.5 \%$ of the subjects were active according to the FAl score which evaluates the everyday activities. Being active discriminated subjects with better physical function. Subjects active according to the FAl score had a higher cognitive level $(p \leq 0.01)$, lower comorbidity $(p=0.02)$ and performed better on all motor function tasks as assessed by walking speed $(p \leq 0.01)$ and the Short Physical Performance battery (SPPB) $(p \leq 0.01)$.

Conclusions: Being physically active seems to be a long term protective factor. In our study, the majority of subjects with Age Related White Mattter Changes (ARWMC) with no or mild Instrumental Activity of Daily Living (IADL) disability did not attain recommended level of activity at first year follow up. Whether or not increasing physical activity may slow down cognitive decline and lessen development of disability in physically inactive subjects with manifest ARWC remains to be studied. Trial registration: not applicable.
\end{abstract}

Keywords: Cognition, Gait, Health, Motor function, Physical activity

\section{Background}

Cognitive decline is among the most feared and economically costly sequela of ageing $[1,2]$. Cognitive decline is associated with a reduction in the ability to perform everyday tasks, make important decisions, and thus live independently $[3,4]$. Ageing is a complex process and

\footnotetext{
* Correspondence: anna.pettersson@ki.se; Milita.crisby@ki.se

'Division of Physiotherapy, Karolinska Institutet, Neurobiology Care Sciences and Society, 23 100, 14183 Huddinge, Sweden

${ }^{2}$ Division of Clinical Geriatrics, Karolinska Institutet, Neurobiology Care

Sciences and Society, Huddinge, Sweden

Full list of author information is available at the end of the article
}

appears to affect white matter integrity and functional connectivity in the brain [5]. Physical fitness and possession of the APOE e4 allele have been shown to be incrementally associated with cognitive change at statistically significant level [6].

Higher levels of physical activity have been associated with larger gray-matter volumes [7]. Furthermore, cardiorespiratory fitness affects white-matter integrity [8, 9], which may consequently have positive effects on functional brain activity in old age [10]. 
Moderate physical activity for at least $30 \mathrm{~min}$, no less than 3 times/week has been reported to maintain cardiovascular fitness [11]. This level of exercise has shown to decrease vascular risk factors and the incidence of coronary heart disease [12]. In addition, low intensity physical activity renders other health benefits such as maintaining physical function, a higher quality of life, and wellbeing [13]. Even low intensity physical activity has been shown to be associated with larger hippocampus volume in older adults [14]. Many of our daily activities include activities that are dependent on lower extremity function, which has been found to be able to predict short-term mortality and nursing home admission in older adults [15-17]. Gait speed alone has been found to predict incident disability in previously nondisabled older people [18].

Age related brain white matter changes, (ARWMC), are hyperintense lesions observed on T2-weighted images on brain magnetic resonance imaging (MRI). ARWMC are common findings in older people and have been associated with cognitive impairment as well as gait disturbances $[19,20]$. Cerebral ischemia related to deep cerebral small vessels of the brain due to aging, arterial hypertension and other vascular risk factors has been suggested as possible causes of ARWMC [21, 22]. The severity of ARWMC on brain MRI has been described by Fazekas et al. as; grade I (punctuate changes), grade II (early confluent changes) and grade III (severe confluent changes) [23]. Gait disturbances may lead to limitations in activities and a restricted ability to participate in life situations and subsequently lead to an inactive life style and increased risk of falls [19, 24, 25]. This has important implications since inactive older people with low physiologic reserves are more vulnerable to disease events and subsequent disability [26, 27]. The present study evaluates cross sectional data of activity level in people with ARWMC in relation to motor performance, cognition and perceived health.

\section{Methods}

\section{Design}

In this cross-sectional study data came from the first year follow up of one of the participating centres of the Leukoaraiosis and Disability study (LADIS) [28]. In brief the LADIS study is a multicentre and multinational longitudinal study with the aim to examine the net contribution of various degrees of ARWMC on the development of disability in older people.

\section{Subjects}

LADIS participants were at entry between 65 and 84 years of age. They had no or mild disability as defined by the Instrumental Activities of Daily Living (IADL). All of them had a contactable informant and had agreed to sign an informed consent prior to participation in the study. Subjects were recruited between 2001 and 2002 through the radiology department where they had presented with cerebral subcortical white matter changes on MRI of any degree. Two of the subjects had been referred to MRI due to cognitive impairment; another five subjects had been referred to MRI due to minor stroke and the remaining subjects with ARWMC were incidentally detected. Subjects were excluded if they were judged likely to drop out due to any severe disease, unable to give informed consent or inability to undergo further MRI scan. Based on the inclusion and exclusion criteria 51 subjects were enrolled in the study. At the first year follow up, data was available for 41 subjects, Fig. 1. The study was approved be the local ethics committee, reference number 01-316.

\section{Materials and procedure}

Subjects underwent a thorough examination according to the LADIS protocol, which has been described in detail elsewhere [28]. In summary these examinations included medical history, social background and assessments of physical and cognitive function and brain MR. The LADIS study includes data on subjects from all European centers up to a 3 year follow-up period [28]. The present study is a sub-study that includes crosssectional data assessed at the first year follow up at Karolinska University Hospital, Huddinge, Sweden. For the purpose of this study an additional evaluation of everyday activities was performed.

\section{Medical history/co-morbidity}

Information on comorbidity came from interviewing the patient and the informant, and from the medical records. Comorbidities included cardiovascular risk factors and age related comorbidities known as possible determinants of disability in the elderly. All of these were defined according to the currently most widely accepted criteria, selected

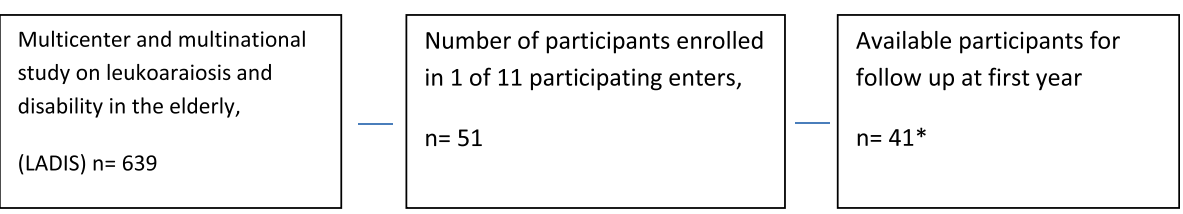

Fig. 1 Participant flow chart. *not available for examination $n=4$, drop out $n=1$, died $n=1$, followed up by telephone interview only $n=4$ 
after a systematic literature search reported in detail elsewhere [28].

\section{Medical history/physical activity}

Physical activity level was classified with a yes or no question. Being physically active was defined according to the American Heart Association (AHA) Scientific definition, (i.e. at least $30 \mathrm{~min}$ of activity and at least 3 times/week) [11].

\section{Additional assessment of every day physical activity}

We were especially interested to look at lower intensities of physical activities since this also may have health benefits for older people. Consequently, for the purpose of the present study the activity level was further assessed with the Frenchay Activities Index (FAI) [29], a questionnaire reflecting lower intensity activities including questions about the frequency of domestic chores, leisure/work and outdoor activities. A high score indicates higher level of activity (max 45). The FAI has been validated in a general population aged 16 and over [30].

\section{Assessment of cognitive function}

General cognitive ability was assessed using the Mini Mental State Examination score (MMSE) [31].

\section{Assessment of physical function}

Physical function was assessed using the Short Physical Performance Battery (SPBB) that includes tests of standing balance, walking speed and time to rise from a chair five times. Subjects are scored $0-4$ depending on time performance, with 0 representing the inability to complete the task and 4 representing the highest level of performance. Maximum score is 12 .

In addition, walking speed $(\mathrm{m} / \mathrm{s})$ was recorded by measuring the free walking speed over an $8 \mathrm{~m}$ course [32].

\section{Evaluation of perceived health}

The subjects' perception of own health status was evaluated using the visual analogue rating scale (VAS) from the EuroQoul/EQ5D [33]. The EQ5D VAS is a vertical $20 \mathrm{~cm}$ visual analogue scale similar to a thermometer. It ranges from worst imaginable health state, 0 , to best imaginable health state, 100 .

\section{MRI scanning/rating of ARWMC}

All subjects had been examined by MRI according to a standard protocol. The degree of ARWMC severity was rated by one of the co-authors, an experienced consultant in neuroradiology (LB), using the visual scale of Fazekas as grade 1 (punctuate), grade 2 (early confluent), grade 3 (confluent) [23]. ARWMC of grade one was denoted as mild, grade 2 as moderate and grade 3 as severe
[28]. Details on the MRI procedure and rating of ARMC are published elsewhere [29].

Subjects characteristics are shown in Table 1.

\section{Statistical analysis}

The subject sample was divided in subjects who were physically active as defined according to the AHA scientific definition [11] and less physically active respectively. In addition, we aimed to study those who were defined active at lower intensities using the FAI score that captures domestic chores, leisure/work and outdoor activities. The maximum score of FAI is 45 which indicate a higher level of such activities. For the purpose of this study we wanted to discriminate between high performers and low performers thus subjects who had a FAI score $\geq$ the median of the whole group were considered active and those subjects below the median were consequently considered inactive. In the analysis, the FAI Score was dichotomised taking the value zero for values below the median/mean and one for values equal to and above the median/mean. The Mann-Whitney $\mathrm{U}$ test was used to look at differences between physically active and physically inactive.

Differences among subjects with various degrees of ARWMC was assessed using Kruskal-Wallis ANOVA.

The variables FAI, SPPB, EQ5D, MMSE, age and number of comorbidities were dichotomised, taking the value zero for values below the median/mean and one for values equal to and above the median/mean. Stepwise logistic and stepwise linear regression analysis were then used to evaluate to what extent physical function (SPPB, walking speed) and health (EQ5D) could be explained by the activity level, degree of ARWMC, age, sex, cognition (MMSE score) and co-morbidity.

Table 1 Characteristics, all subjects $(n=41)$. Median (range), Mean \pm SD

\begin{tabular}{ll}
\hline Number of subjects & 41 \\
Age (yrs) & $75 \pm 4.9$ \\
Sex (Males/Females) & $20 / 21$ \\
Mini Mental State Examination, MMSE (score) & $27(20-30)$ \\
Number of comorbidities & $1.6 \pm 1.4$ \\
Number of persons active according to AHA & $15 / 26$ \\
definition yes/no & \\
The Frenchay Activities Index, FAI (score) & $26(6-33)$ \\
Short Physical Performance Battery, SPPB (score) & $9(3-12)$ \\
Chair- stands (s) & $17,4 \pm 4.7$ \\
Walking speed (mean m/s) & $1.01 \pm 0.2$ \\
Euro-Quol, EQ5D (median VAS score) & $75(30-95)$ \\
\hline
\end{tabular}




\section{Results}

According to the AHA scientific definition 36\% $(n=15)$ were physically active while $27.5 \%(n=11)$ were active according to the FAI score (every day activities). Subjects being physically active according to the AHA scientific definition had significantly better SPPB-scores, ( $p$-value $0.01)$. Subjects active according to the FAI score had a higher cognitive level $(\mathrm{p}=\leq 0.01)$, less comorbidity $(p=0.02)$ and performed better on all motor function tasks such as the walking speed $(p \leq 0.01)$ and the SPPB score $(p \leq 0.01)$ as shown in Table 2 .

\section{Degree of ARWMC}

There were no significant differences regarding age, sex, cognitive level, activity level, motor performance or perceived health between subjects with different degrees of ARWMC.

\section{Tests of physical function SPPB}

Stepwise logistic regression analyses showed that cognitive level as measured with MMSE and the number of comorbidities was significantly related to the performance on the SPPB score ( $p$-value 0.01 and 0.02 respectively).

The OR for having a SPPB score equal to or above the median was 1.4 times higher for those with a higher cognitive level as measured with MMSE, (95\% confidence interval, 1.07-1.85).

Subjects with co-morbidities equal to or above the mean for the whole group were less likely to perform better on SPPB (OR 0.48, 95\% confidence interval 0.25-0.91).

\section{Walking speed}

Walking speed was significantly related to the subjects' cognitive level as assessed by the MMSE $(p<0,005)$. In addition, the walking speed correlated to the number of comorbidities and moderate degree of ARWMC ( $p$-value 0.02 and 0.04 respectively).

The MMSE scores, number of co-morbidities and degree of ARWMC appeared to be three independent

Table 2 Differences in age, sex, co-morbidity, cognitive and physical function and health in active/inactive subjects according to FAl $(n=40)$ Median (range), Mean \pm SD

\begin{tabular}{llll}
\hline Variable & $\begin{array}{l}\text { Physically active } \\
n=11\end{array}$ & $\begin{array}{l}\text { Physically less active } \\
n=29\end{array}$ & $p$-value \\
\hline Age (yrs) & $74 \pm 5.4$ & $77 \pm 3.5$ & 0.12 \\
Sex (M/F) & $9 / 12$ & $12 / 7$ & 0.27 \\
Co-morbidities (n) & $1.0 \pm 1.1$ & $2.2 \pm 1.5$ & 0.02 \\
MMSE (score) & $29(21-30)$ & $25(20-30)$ & $\leq 0.01$ \\
SPPB (score) & $10(7-12)$ & $7(3-11)$ & $\leq 0.01$ \\
Walking speed (m/s) & $1.1 \pm 0.2$ & $0.9 \pm 0.2$ & $\leq 0.01$ \\
EQ5D (VAS score) & $80(30-95)$ & $70(30-90)$ & 0.24 \\
\hline
\end{tabular}

variables which explained $34 \%$ of the variation in the walking speed.

\section{Perceived health \\ EQ5D}

Only co-morbidities were significantly related to perceived health as assessed with the EQ5D $(p<0,005)$. Subjects with a number of co-morbidities equal to or above the mean $(\mathrm{m}=1.6 \pm 1.4)$ were less likely to score high on the EQ5D, $(\mathrm{OR}=0.39 ; 95 \%$ confidence interval: $0.21-0.73)$.

\section{Discussion}

The majority of the subjects in this study were not active at the suggested level according to the AHA statement. There was a clear association between the activity level of the subjects according to the AHA's definition and to better physical function such as motor performance and walking speed. A higher degree of physical activity has been shown to attenuate age-related myelin declines in portions of the corpus callosum that interconnect homologous premotor cortex regions involved in motor planning [8]. A previous 3-year prospective study has shown that both sports and non-sports activities (walking and household) have been found to be a determinant of change in mobility performance. Indeed, this effect was independent of presence of chronic disease. Furthermore, the study showed that the subjects who started being active during follow up had a lesser degree of decline in mobility performance compared to those who remained at the same activity level [34].

We also found that the activity level of the subjects correlated to the degree of ARWMC. The positive correlation seen between physical activity and motor performance, cognition and walking speed remained significant even after correction for the demographic variables and were independent of the reported gait disturbances and previous falls. Studies have shown a clear association between white matter integrity and functional connectivity in the brain [35] and being physically active appears to be protective for maintaining white matter integrity [36]. These protective effects could be partly due to the positive effects seen in the regulation of blood pressure and improvements of the glucose metabolism [37, 38].

A major limitation of this study is its' small sample size. The cross sectional design also makes it difficult to determine the temporal relationship between exposure and outcome and does not allow to draw conclusions on causality.However, it is reasonable to consider the possibility that comorbidity, physical activity, physical function and cognition are interrelated. Co-morbidities may incorporate factors that are perceived as barriers for taking part in physical activity [39]. Such factors may be 
tiredness, feelings of discomfort or pain. This may lead to a downward spiral of decreasing activity level eventually causing motor disability. Moreover, many of the comorbidities were cardiovascular risk factors that are thought to play a role in the development of ischemic events and subsequent ARWMC and impaired cognitive function [21, 22]. Executive functions are often impaired in subjects with ARWMC, decrements in executive function may cause less initiative to physical activity [22].

Physical activity has previously been linked to physical function [40,41] and cognition [42]. In a recent publication from the whole cohort included in the LADIS study, being physically active was associated with reduced risk of cognitive impairment and reduced in more than half, the risk for vascular dementia. However, physical activity did not influence evolution of Alzheimer dementia [43].

\section{Conclusions}

Being physically active seems to be a long term protective factor for cognitive function. In our study, the majority of subjects with ARWMC with no or mild IADL disability did not attain recommended level of activity at first year follow up. Whether or not increasing physical activity may slow down cognitive decline and lessen development of disability in physically inactive subjects with manifest ARWC remains to be studied.

\section{Abbreviations \\ AHA: American Heart Association; ARWMC: Age Related White matters Changes; FAl: Frenchay Activities Index; IADL: Instrumental Activities of Daily Living; LADIS: Leukoaraiosis and Disability study; MMSE: Mini Mental State Examination score; MRI: Magnetic Resonance Imaging; SPBB: Short Physical Performance Battery; VAS: Visual Analogue rating Scale}

\section{Acknowledgements}

Not applicable.

\section{Funding}

We'd like to thank Dr. Carl Herlitz och Mer Håkan Erlandsson for providing research resourses for Milita Crisby during the drafting of the manuscript and Gun \& Bertil Stohnes foundation for providing research resources for Anna Pettersson.

\section{Availability of data and materials}

The data that support the findings of this study are available from an electronic case record but restrictions apply to the availability of these data, which were used under license for the current study, and so are not publicly available. Data are however available from the authors upon reasonable request.

\section{Authors' contributions}

AFP has been involved in the design of the study and assessments for the motor function and SPPB tests as well as the statistical analysis and the drafting of the manuscript. LOW has been involved in the design of the study. LB been responsible for the acquisition, selection, analysis and interpretation of the MRI scans.. KA has Performed and analysed the cognitive tests. EO has been involved in the design of the study. HBZ has been involved in the design of the study. MC has recruited the patients in the study, contributed to the analysis and the drafting of the manuscript. All authors made critical revisions and approved the submission.

\section{Ethics approval and consent to participate}

The study was approved be the local ethics committee, reference number 01-316. Participant's signed an informed consent prior to participation in the study.

\section{Consent for publication}

Not applicable.

\section{Competing interests}

The authors declare that they have no competing interests.

\section{Publisher's Note}

Springer Nature remains neutral with regard to jurisdictional claims in published maps and institutional affiliations.

\section{Author details}

${ }^{1}$ Division of Physiotherapy, Karolinska Institutet, Neurobiology Care Sciences and Society, 23 100, 14183 Huddinge, Sweden. ${ }^{2}$ Division of Clinical Geriatrics, Karolinska Institutet, Neurobiology Care Sciences and Society, Huddinge, Sweden. ${ }^{3}$ Division of Radiology, CLINTEC Department, Karolinska Institutet, Huddinge, Sweden. ${ }^{4}$ Department of Clinical Psychology, Helsinki University, Helsinki, Finland. ${ }^{5}$ Department of Neurology, Universitätsklinikum Mannheim, University of Heidelberg, Heidelberg, Germany.

Received: 9 March 2017 Accepted: 4 July 2017

Published online: 12 July 2017

\section{References}

1. Wimo $L$, Jönsson J, Bond $M$, Prince $B$, Winblad B. The worldwide impact of dementia 2010. Alzheimers Dement. 2013:9:1-11. e3

2. Harper S. Economic and social implications of aging societies. Science. 2014; 346:587-91.

3. Tucker-Drob EM. Neurocognitive functions and everyday functions change together in old age. Neuropsychology. 2011;25:368-77.

4. Boyle PA, Yu L, Wilson RS, Gamble K, Buchman AS, Bennett DA. Poor decision making is a consequence of cognitive decline among older persons without Alzheimer's disease or mild cognitive impairment. PLOS One. 2012; doi:10.1371/journal.pone.0043647.

5. Yang AC, Tsai SJ, Liu ME, Huang CC, Lin CP. The Association of Aging with white matter integrity and functional connectivity hubs. Front Aging Neurosci. 2016:8:143.

6. Ritchie SJ, Tucker-Drob EM, Cox SR, Corley J, Dykiert D, et al. Predictors of ageing-related decline across multiple cognitive functions. Intelligence. 2016:59:115-26.

7. Papenberg G, Ferencz B, Mangialasche F, Mecocci P, Cecchetti R, et al. Physical activity and inflammation: effects on gray-matter volume and cognitive decline in aging. Hum Brain Mapp. 2016;37:3462-73.

8. Johnson NF, Kim C, Clasey JL, Bailey A, Gold BT. Cardiorespiratory fitness is positively correlated with cerebral white matter integrity in healthy seniors. Neurolmage. 2012;59:1514-23.

9. Voss MW, Heo S, Prakash RS, Erickson Kl, Alves $\mathrm{H}$, et al. The influence of aerobic fitness on cerebral white matter integrity and cognitive function in older adults: results of a one-year exercise intervention. Hum Brain Mapp. 2012;34:2972-85.

10. Suo C, Singh MF, Gates N, Wen W, Sachdev P, et al. Therapeutically relevant structural and functional mechanisms triggered by physical and cognitive exercise. Mol Psychiatry. 2016;21:1633-42.

11. Garber CE, Blissmer B, Deschenes MR, Franklin BA, Lamonte MJ, Lee IM, Nieman DC, Swain DP. American College of Sports Medicine position stand. Quantity and quality of exercise for developing and maintaining cardiorespiratory, musculoskeletal, and neuromotor fitness in apparently healthy adults: guidance for prescribing exercise. Med Sci Sports Exerc. 2011; doi:10.1249/MSS.0b013e318213fefb.

12. Villeneuve PJ, Morrison HI, Craig CL, Schaubel DE. Physical activity, physical fitness, and risk of dying. Epidemiology. 1998;9(6):626-31.

13. Spirduso WW, Cronin DL. Exercise dose-response effects on quality of life and independent living in older adults. Med Sci Sports Exerc. 2001; 33(Suppl):598-608.

14. Varma VR, Chuang YF, Harris GC, Tan EJ, Carlson MC. Low-intensity daily walking activity is associated with hippocampal volume in older adults. Hippocampus. 2015;25:605-15. 
15. Landi F, Cesari M, Onder G, Lattanzio F, Gravina EM, Bernabei R. Physical activity and mortality in frail, community-living elderly patients. J Gerontol A Biol Sci Med Sci. 2004;59:833-7.

16. Kokkinos P, Myers J, Faselis C, Panagiotakos DB, Doumas M, Pittaras A, Manolis A, Kokkinos JP, Karasik P, Greenberg M, Papademetriou V, Fletcher R. Exercise capacity and mortality in older men: a 20-year follow-up study. Circulation. 2010;122:790-7.

17. Guralnik JM, Simonsick EM, Ferrucci L, Glynn RJ, Berkman LF, Blazer DG, et al. A short physical performance battery assessing lower extremity function: association with self-reported disability and prediction of mortality and nursing home admission. J Gerontol. 1994;49:M85-94.

18. Guralnik JM, Ferrucci L, Pieper CF, Leveille SG, Markides KS, Ostir GV, et al. Lower extremity function and subsequent disability: consistency across studies, predictive models, and value of gait speed alone compared with the short physical performance battery. J Gerontol A Biol Sci Med Sci. 2000;55:M221-31.

19. Longstreth WT Jr, Arnold AM, Manolio TA, Burke GL, Bryan N, Jungreis CA, et al. Clinical correlates of ventricular and sulcal size on cranial magnetic resonance imaging of 3,301 elderly people. The cardiovascular health study. Collaborative research group. Neuroepidemiology. 2000;19:30-42.

20. Baezner H, Blahak C, Poggesi A, Pantoni L, Inzitari D, Chabriat H, et al. Association of gait and balance disorders with age-related white matter changes: the LADIS study. Neurology. 2008;70:935-42.

21. Pantoni L, Garcia JH. Pathogenesis of leukoaraiosis: a review. Stroke. 1997;28:652-9.

22. Pugh KG, Lipsitz LA. The microvascular frontal-subcortical syndrome of aging. Neurobiol Aging. 2002;23:421-31.

23. Fazekas F, Barkhof $F$, Wahlund LO, Pantoni L, Erkinjuntti T, Scheltens $P$, et al. CT and MRI rating of white matter lesions. Cerebrovasc Dis. 2002; 13(Suppl 2):31-6.

24. Baloh RW, Yue Q, Socotch TM, Jacobson KM. White matter lesions and disequilibrium in older people. I Case-control comparison. Arch Neurol. 1995:52:970-4

25. Briley DP, Wasay M, Sergent S, Thomas S. Cerebral white matter changes (leukoaraiosis), stroke, and gait disturbance. J Am Geriatr Soc. 1997:45:1434-8.

26. Rantanen T, Guralnik JM, Ferrucci L, Penninx BW, Leveille S, Sipila S, et al. Coimpairments as predictors of severe walking disability in older women. J Am Geriatr Soc. 2001;49:21-7.

27. Gill TM, Allore H, Holford TR, Guo Z. The development of insidious disability in activities of daily living among community-living older persons. Am J Med. 2004:117:484-91.

28. Pantoni L, Basile AM, Pracucci G, Asplund K, Bogousslavsky J, Chabriat H, et al. Impact of age-related cerebral white matter changes on the transition to disability - the LADIS study: rationale, design and methodology. Neuroepidemiology. 2005;24:51-62.

29. Wade DT, Legh-Smith J, Langton HR. Social activities after stroke: measurement and natural history using the Frenchay activities index. Int Rehabil Med. 1985;7:176-81.

30. Turnbull JC, Kersten P, Habib M, McLellan L, Mullee MA, George S. Validation of the Frenchay activities index in a general population aged 16 years and older. Arch Phys Med Rehabil. 2000;81:1034-8.

31. Folstein MF, Folstein SE, McHugh PR. "mini-mental state". A practical method for grading the cognitive state of patients for the clinician. J Psychiatr Res. 1975;12:189-98.

32. Guttmann CR, Benson R, Warfield SK, Wei X, Anderson MC, Hall CB, et al. White matter abnormalities in mobility-impaired older persons. Neurology. 2000;54:1277-83.

33. Brooks R. EuroQol: the current state of play. Health Policy. 1996;37:53-72

34. Visser M, Pluijm SM, Stel VS, Bosscher RJ, Deeg DJ. Physical activity as a determinant of change in mobility performance: the longitudinal aging study Amsterdam. J Am Geriatr Soc. 2002;50:1774-81.

35. Yang AC, Tsai SJ, Liu ME, Huang CC, Lin CP. The Association of Aging with white matter integrity and functional connectivity hubs. Front Aging Neurosci. 2016;15(8):143

36. Brain and White Matter Hyperintensity Volumes After 10 Years of Random Assignment to Lifestyle Intervention. Espeland MA, Erickson K, Neiberg RH, Jakicic JM, Wadden TA, Wing RR, Desiderio L, et al. Diabetes Care. 2016; doi: 10.2337/dc15-2230.

37. Whelton SP, Chin A, Xin X, He J. Effect of aerobic exercise on blood pressure: a meta-analysis of randomized, controlled trials. Ann Intern Med. 2002:136:493-503.
38. Tuomilehto J, Lindström J, Eriksson JG, Valle TT, Hämäläinen $H$, llanne-Parikka $P$, et al. Prevention of type 2 diabetes mellitus by changes in lifestyle among subjects with impaired glucose tolerance. N Engl J Med. 2001;344:1343-50.

39. Ferrucci L, Bandinelli S, Benvenuti E, Di lorio A, Macchi C, Harris TB, et al. Subsystems contributing to the decline in ability to walk: bridging the gap between epidemiology and geriatric practice in the InCHIANTI study. J Am Geriatr Soc. 2000;48:1618-25.

40. Wong CH, Wong SF, Pang WS, Azizah MY, Dass MJ. Habitual walking and its correlation to better physical function: implications for prevention of physical disability in older persons. J Gerontol A Biol Sci Med Sci. 2003;58:555-60.

41. Newman AB, Haggerty CL, Kritchevsky SB, Nevitt MC, Simonsick EM. Walking performance and cardiovascular response: associations with age and morbidity-the health, aging and body composition study. J Gerontol A Biol Sci Med Sci. 2003;58:715-20

42. Laurin D, Verreault R, Lindsay J, MacPherson K, Rockwood K. Physical activity and risk of cognitive impairment and dementia in elderly persons. Arch Neurol. 2001;58:498-504.

43. Verdelho A, Madureira S, Ferro JM, Baezner H, Blahak C, et al. LADIS study. Physical activity prevents progression for cognitive impairment and vascular dementia: results from the LADIS (Leukoaraiosis and disability) study. Stroke. 2012:43:3331-5

\section{Submit your next manuscript to BioMed Central and we will help you at every step:}

- We accept pre-submission inquiries

- Our selector tool helps you to find the most relevant journal

- We provide round the clock customer support

- Convenient online submission

- Thorough peer review

- Inclusion in PubMed and all major indexing services

- Maximum visibility for your research

Submit your manuscript at www.biomedcentral.com/submit
) Biomed Central 